\title{
Clinical, laboratory profile $\&$ antibiotic use in first time Wheezers in the tertiary care centre in the rural area
}

\author{
Bala Gopal M${ }^{1}$, Babji NSR ${ }^{2}$, Vinayagamoorthy $V^{3}$, Venkata NK $^{4}$ \\ ${ }^{1}$ Dr M. Bala Gopal, Associate Professor, Department of Pediatrics, ${ }^{2}$ Dr N. Shiva Ramakrishnan Babji, Assistant \\ Professor, ${ }^{3}$ Dr Vinayagamoorthy Venugopal, Assistant Professor, Department of Community Medicine, ${ }^{4}$ Dr. Venkata \\ Naveen Kumar, Assistant Professor, Department of Medical Pharmacology, all authors are affiliated with Sri Manakula \\ Vinayagar Medical College and Hospital, Puducherry, India.
}

Address for Correspondence: Dr M. Bala Gopal, Email: gopalneo@yahoo.co.in

\begin{abstract}
Background: Acute bronchiolitis is primarily due to acute viral infection. There is need for the clinicians to adopt judicious use of antibiotics with understanding of the aetiopathogenesis clinical course, complications and the outcome. It is possible to use the antimicrobials rationally. Objective: To evaluate the antibiotic requirement from the data collected from the first time wheezers among the hospitalized patients in the pediatric tertiary care centre cum teaching hospital in the rural area. The data was analyzed to justify the antimicrobial use in clinical practice in children with acute bronchiolitis. Method: This is retrospective study with cross sectional analysis. Data was collected from the patients admitted during the year 2015 January to December, Admission complaints, positive clinical signs, symptoms, and lab investigations were collected to correlate with antibiotic usage in the patients diagnosed as acute bronchiolitis. New symptoms during treatment, duration of stay and outcome were recorded to compare antibiotic group with non antibiotic group. The data was analyzed and compared with other studies. Results: Out of total 70 cases 7 cases were excluded as per exclusion criteria. 63 cases were included in our study. 63 percent of cases are less than 6 months in our study. $71 \%$ of cases are males. $47 \%$ of cases have received either oral or intravenous antibiotics. The mean duration of stay in antibiotic group is 6.3 days when compared to 4.2 days in non antibiotic group. Conclusion: with good correlation of clinical and laboratory parameters antibiotic use can be restricted in acute bronchiolitis which is due to acute viral disease.
\end{abstract}

Keywords: Acute bronchiolitis. Antibiotics, Lab parameters.

\section{Introduction}

The respiratory infection is the common cause for the children to be brought to the pediatric department [1]. Bronchiolitis is an acute episode of wheeze with a viral prodrome in children less than 2 years of age. They present with respiratory distress which begins as upper respiratory illness. Fever will occur in the first few days of the illness and it may be of low grade in respiratory syncytial virus infection. Subsequently the fever can be intermittent also [2]. Even though with the grade of the fever one cannot differentiate between bacterial and viral infections, clinical pattern of individual viral infections helps to differentiate clinically as well as with laboratory support also [2]. In case of seasonal flu presenting as acute bronchiolitis the fever will be of

Manuscript received: $10^{\text {th }}$ October 2016

Reviewed: $24^{\text {th }}$ October 2016

Author Corrected; $15^{\text {th }}$ November 2016

Accepted for Publication: $30^{\text {th }}$ November 2016 high grade [3]. In respiratory syncytial viral infection the fever will be present in early part of the course of the illness [4]. Whereas in bacterial infection as in the case of pneumonia fever will be persistent, high grade and associated with other constitutional symptoms. In case of bacterial infection, the child will be sick looking; toxic, reduced activity and refusal of feeds will be there [5].

Good history taking and clinical assessment will help the clinician to narrow down the possibility of acute bacterial infection as well as coexisting acute serious bacterial infection in a child with acute bronchiolitis. In clinical practice child presenting with bilateral diffuse wheezing following upper respiratory symptom do not require routine antibiotics [6]. Literature references show no usefulness of routine antibiotics in acute 
bronchiolitis. Routine parenteral antibiotic use will increase the cost of treatment as well as complications like antibiotic associated diarrhea, secondary fungal infection and prolonged stay of the patients [7]. The most important problem with indiscriminate use of antibiotic use is development of multi-drug resistant bacteria. This is a major threat in extremes of age as well as for the children admitted in I.C.U with preexisting chronic illness. There are guidelines and recommendations for the prevention of emerging bacterial drug resistance. With simple laboratory support like complete haemogram chest skiagram and with careful interpretation one can restrict the antibiotic use in first time wheezers [7]. Now with better understanding of individual viral agents and their clinical behavior and radiological features one can identify and differentiate them. Respiratoty syncytial infection can involve any age group, but it presents with respiratory distress when it affects children with less than 2 years of age [8]. Older children or adults when they are infected with respiratory syncytial virus they present as common cold or upper respiratory infection. In lower or lower middle socioeconomic group when they live in an overcrowded condition they acquire infection very early. Infants presenting as first time wheeze, clinically has to be differentiated from other kinds of noisy breathing [9]. Many respiratory conditions can present with noisy breathing which are the differential diagnosis for acute bronchiolitis especially when the presentation is atypical [9]. In our study we have included only those cases presenting with bilateral wheeze and with no previous history suggestive of respiratory distress or noisy breathing.

First episode of wheeze may be due to viral infection or first episode of hyper-reactive airway disease. In uncomplicated cases both conditions do not require antibacterial treatment. So the first episode of wheezers was targeted to analyze the antibiotic use in clinical practice [10]. There are very few studies conducted regarding antibiotic use in the first time wheezers in the developing countries. In this study we have analyzed the clinical features laboratory reports, course of the illness, complications, treatment given and the outcome. In clinical practice presence of fever is not to be equated with antibiotic requirement. Fever can be due to non infective causes as well as due to non bacterial infective agents also [8]. Even if the baby is started with antibiotics once clinical re-assessment and laboratory parameters rules out the possibility of acute bacterial infection, the antibiotics can be withheld. Formulation of protocols based on the standard guidelines will help the youngsters to take decision in clinical situations. Discussion with parents about the cause of the illness and the course of the disease will make them to cooperate with treating physician and that helps to practice the best possible treatment for the children.

Subjects and methods: This is retrospective study done in the pediatric department in the tertiary care cum teaching institution serving the rural population. The data was collected from the case sheets of the patients admitted with the final diagnosis of acute bronchiolitis from January 2015 to December 2015.The clinical features, investigations done for the patients, course of the illness and the treatment given were recorded. Clinical features and the lab parameters were correlated with antibacterial use in the patients diagnosed as acute bronchiolitis. Group of children with antibiotics used were compared with non antibiotic group. This study was compared with studies with documented coexisting bacterial infections warranting antibacterial treatment.

Study design: Retrospective study with cross sectional analysis.

Inclusion criteria: All children admitted with final diagnosis as acute bronchiolitis during the year 2015 from January to December 2015 were included in this study.

Exclusion criteria: children with preexisting illness and children who discontinued the treatment were excluded from the study.

Methodology: Structured data sheet with basic details of the patient, detailed history, clinical examination findings; investigations clinical course, treatment and outcome were recorded from the patient's case sheets after the approval from the ethical committee. The collected data was evaluated.

Statistical analysis: Chi-square test was used for statistical analysis using SPSS software and P-value less than $<0.05$ was considered as significant result

\section{Results}

Out of total cases admitted in the pediatric department during the year 2015 between January to December, 326 cases were respiratory cases. Among the various respiratory syndromes 70 cases were due to acute bronchiolitis. 7 cases were 
excluded from the study as per exclusion criteria (one case had preexisting congenital heart disease, (ventricular septal defect) 6 patients were shifted to another centre as per the parents convenience (for invasive ventilator support) All the patients in our study group belonged to lower or lower middle socioeconomic group. Among the 63 cases included in our study as first time wheezer $40(63.5 \%)$ were below 6months and $20(23 \%)$ were above 6months.Analysis of sex incidence shows that $45(71 \%)$ were males and the remaining $18(28 \%)$ were females. The approximate sex ratio as per incidence (male to female) is 2.5:1 in our study. The analysis of clinical features showed that the respiratory prodrome (features of upper respiratory infection like running nose) was seen in 54 (85.7\%) cases. Low grade fever at the onset of illness was noticed in 48 (76.2\%) of cases. 9 (14.3\%) cases had loose stools during the course of the illness. Analysis of clinical features shows, all the cases in our study group presented with respiratory distress (tachypnea with or without chest retractions) and bilateral diffuse rhonchi with no previous history of wheeze [Table-1].

Table-1: Details of demographic features, clinical pictures and investigations carried out among study participants. $(\mathrm{N}=63)$.

\begin{tabular}{|c|c|c|c|}
\hline Sl. No. & Characteristics of study participants & Frequency & Percentage \\
\hline \multirow[t]{3}{*}{1} & \multicolumn{3}{|l|}{ Age category in months } \\
\hline & $\leq 6$ & 40 & 63.5 \\
\hline & $>6$ & 23 & 36.5 \\
\hline \multirow[t]{3}{*}{2} & \multicolumn{3}{|l|}{ Sex } \\
\hline & Male & 45 & 71.4 \\
\hline & Female & 18 & 28.6 \\
\hline \multirow[t]{6}{*}{3} & \multicolumn{3}{|l|}{ Clinical features } \\
\hline & Respiratory prodrome & 54 & 85.7 \\
\hline & Fever & 48 & 76.2 \\
\hline & Loose stools & 9 & 14.3 \\
\hline & Tachypnoea with wheeze & 39 & 61.9 \\
\hline & Retractions with wheeze & 24 & 38.1 \\
\hline 4 & \multicolumn{3}{|l|}{ Laboratory parameters } \\
\hline \multirow[t]{5}{*}{ A } & \multicolumn{3}{|l|}{ Total count (cells/cu.mm) } \\
\hline & Normal & 18 & 28.6 \\
\hline & $11,000-15,000$ & 31 & 49.2 \\
\hline & $15,000-20,000$ & 11 & 17.5 \\
\hline & $>20,000$ & 3 & 4.7 \\
\hline \multirow[t]{3}{*}{ B } & \multicolumn{3}{|l|}{ Differential count } \\
\hline & Lymphocyte predominance & 39 & 61.9 \\
\hline & Polymorh predominance & 6 & 9.5 \\
\hline \multirow[t]{4}{*}{$\mathrm{C}$} & \multicolumn{3}{|l|}{ Haemoglobin (g/dl) } \\
\hline & Normal & 29 & 46 \\
\hline & Mild anemic & 19 & 30.2 \\
\hline & Moderate anemic & 15 & 23.8 \\
\hline \multirow[t]{5}{*}{5} & \multicolumn{3}{|l|}{ X-ray findings } \\
\hline & Normal & 17 & 27 \\
\hline & Bilateral hyperventilation & 31 & 49.2 \\
\hline & $\begin{array}{l}\text { Bilateral hyperventilation with peribronchial vascular } \\
\text { prominence }\end{array}$ & 12 & 19 \\
\hline & Pnuemonitis & 3 & 4.8 \\
\hline 6 & Antibiotics usage & 30 & 47.6 \\
\hline
\end{tabular}

Analysis of lab parameters showed complete haemogram was normal in $18(28.6 \%)$ cases. The total count was mildly elevated between 11,000 to 15,000 in $31(49.2 \%)$ cases. Moderately elevated from 15,000 to 20,000 in 11 (17.5\%) cases. The total count was seen more than 20,000 in $3(4.7 \%)$ cases. when the differential count was analyzed among the cases 
Table-2: Profile of antibiotics prescribed.

\begin{tabular}{|c|c|c|c|}
\hline SI. No. & Antibiotics type & Frequency $(\mathbf{N}=\mathbf{3 0}) *$ & Percentage $^{*}$ \\
\hline 1 & Ceftriaxone & 9 & 14.2 \\
\hline 2 & Cefataxim & 4 & 6.3 \\
\hline 3 & Amoxycillin & 1 & 1.6 \\
\hline 4 & Ampicillin & 7 & 11.1 \\
\hline 5 & Amoxyclauv & 3 & 4.7 \\
\hline 6 & Azithromycin & 10 & 15.9 \\
\hline
\end{tabular}

Note: * Not mutually exclusive.

Table-3: Comparison between age and duration of hospital stay between study subjects $(\mathrm{N}=63)$

\begin{tabular}{|c|c|c|c|c|}
\hline \multirow{2}{*}{ Sl. No } & Characteristics & \multicolumn{2}{|c|}{ Antibiotic usage } & \multirow{2}{*}{ p value\# } \\
\cline { 3 - 4 } & & Yes (N=30) & No (N=33) & \\
\hline 1 & Mean (SD) age in months & $6.7(3)$ & $6.5(2.9)$ & 0.87 \\
\hline 2 & Mean (SD) hospital stay in days & $6.3(2.4)$ & $4.2(1.3)$ & $<0.001^{*}$ \\
\hline
\end{tabular}

\# $\mathrm{p}$ value based on independent $\mathrm{t}$ test. * Statistically significant $(\mathrm{p}<0.05)$

Table-4: Comparison between clinical features between study subjects $(\mathrm{N}=63)$

\begin{tabular}{|c|c|c|c|c|}
\hline \multirow{2}{*}{ Sl. No } & Clinical features & \multicolumn{2}{|c|}{ Antibiotic usage } & \multirow{2}{*}{ p value\# } \\
\cline { 3 - 4 } & & Yes $(\mathrm{N}=30), \mathrm{n}(\%)$ & No $(\mathrm{N}=33), \mathrm{n}(\%)$ & \\
\hline 1 & Respiratory prodrome & $25(83.3)$ & $29(87.9)$ & 0.60 \\
\hline 2 & Fever & $23(76.7)$ & $25(75.8)$ & 0.93 \\
\hline 3 & Loose stools & $7[23.3]$ & $2[6.1]$ & $0.05^{*}$ \\
\hline 4 & Tachypnoea with wheeze & $18(60)$ & $21(63.6)$ & 0.76 \\
\hline 5 & Retractions with wheeze & $12(40)$ & $12(36.4)$ & 0.76 \\
\hline
\end{tabular}

\# $\mathrm{p}$ value based on chi-square test, ${ }^{*}$ statistically significant $(\mathrm{p}<0.05)$

Table-5: Comparison between investigations carried out between study subjects $(\mathrm{N}=63)$.

\begin{tabular}{|c|c|c|c|c|}
\hline \multirow{2}{*}{$\begin{array}{l}\text { Sl. } \\
\text { No }\end{array}$} & \multirow[t]{2}{*}{ Investigations } & \multicolumn{2}{|c|}{ Antibiotic usage } & \multirow[t]{2}{*}{ p value\# } \\
\hline & & Yes $(\mathrm{N}=30), \mathrm{n}(\%)$ & No $(\mathrm{N}=33), \mathrm{n}(\%)$ & \\
\hline \multirow[t]{5}{*}{1} & \multicolumn{3}{|l|}{ Total count } & \multirow{6}{*}{0.85} \\
\hline & Normal & $8(26.6)$ & $10(30.3)$ & \\
\hline & $11,000-15,000$ & $14(46.6)$ & $17(51.5)$ & \\
\hline & $15,000-20,000$ & $6(20)$ & $5(15.1)$ & \\
\hline & $>20,000$ & $2(6.6)$ & $1(3.0)$ & \\
\hline \multirow[t]{3}{*}{2} & \multicolumn{3}{|l|}{ Differential count } & \\
\hline & Lymphocyte predominance & $17(56.7)$ & $23(69.7)$ & 0.28 \\
\hline & Polymorh predominance & $5[16.6]$ & $1(3)$ & $0.03 *$ \\
\hline \multirow[t]{4}{*}{3} & \multicolumn{3}{|l|}{ Haemoglobin (g/dl) } & \multirow{4}{*}{0.11} \\
\hline & Normal & $10(33.3)$ & $19(57.6)$ & \\
\hline & Mild anaemic & $10(33.3)$ & $9(27.3)$ & \\
\hline & Moderate anaemic & $10(33.3)$ & $5(15.2)$ & \\
\hline \multirow[t]{5}{*}{4} & \multicolumn{3}{|l|}{ Chest X-ray finding } & \multirow{5}{*}{$0.02 *$} \\
\hline & Normal & $7(23.3)$ & $10(30.3)$ & \\
\hline & Bilateral hyperventilation & $11(36.7)$ & $20(60.6)$ & \\
\hline & $\begin{array}{l}\text { Bilateral hyperventilation with } \\
\text { peribronchial vascular prominence }\end{array}$ & $9(30)$ & $3(9.1)$ & \\
\hline & Pnuemonitis & $3(10)$ & 0 & \\
\hline
\end{tabular}


\# $\mathrm{p}$ value based on chi-square test, * Statistically significant $(\mathrm{p}<0.05)$

with elevated total count majority of the cases, [39 (61.9\%)] had lymphocyte predominance. All the 3 cases with total count of $>20,000$ also had lymphocyte predominance in the differential count. In 6 (9.5\%) cases polymorph predominance was present. Haemoglobin was normal in $29(46 \%)$ cases. 34 (54\%) cases were anemic as per W.H.O cut off value of $11 \mathrm{gm} \%$ for this age group.19 (30.2\%) cases were mildly anemic with Hb level between 10 to $10.9 \mathrm{gm} .15$ (23.8\%) cases were moderately anemic with $\mathrm{Hb}$ level between 7 to $9.9 \mathrm{gm}$. x-ray findings revealed normal in 17 (27\%) cases.31 (49.2\%) cases had bilateral hyperventilation.12 (19\%) cases had bilateral hyperventilation with bilateral diffuse peribronchial cuffing/ vascular prominence (peribronchial thickening). In 3 (4.8\%) cases, patches of pneumonitis was seen [Table-1,4 \& 5].

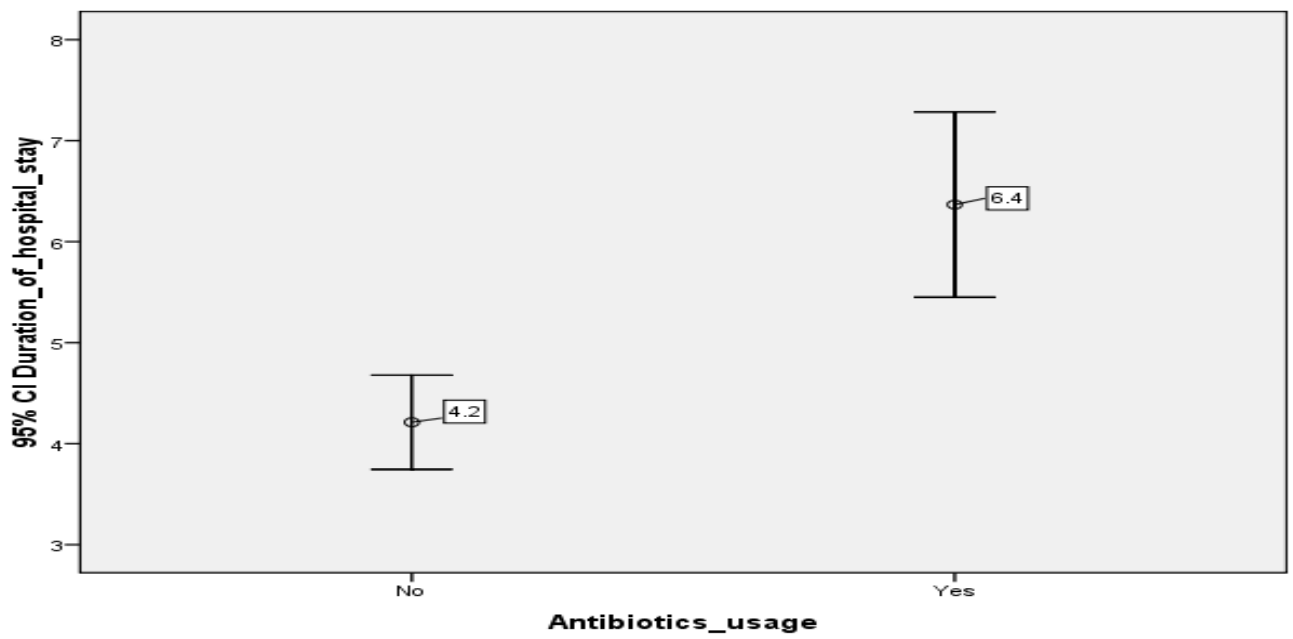

Figure-1: Comparison of mean duration of hospital stay among study subjects based on the usage of antibiotics. (P value $<0.001$ )

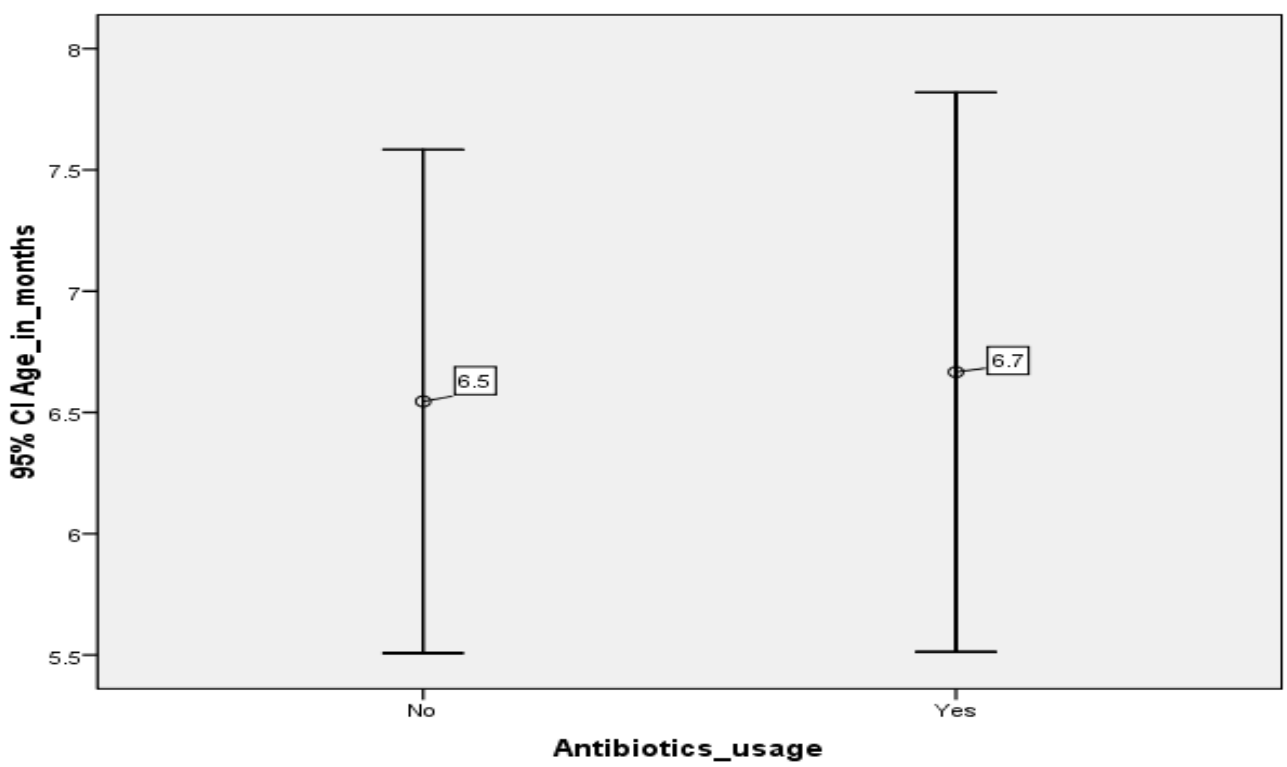

Figure-2: Comparison of mean age of study subjects based on the usage of antibiotics (p value 0.87 ).

Among the 63 cases 30 (47\%) cases have received either oral or parenteral antibiotics during the course of stay. 26 cases have received single antibiotic therapy. Azithromycin and ceftriaxone are the frequently used antibiotics. 4 cases have received 2 antibiotics (more than one antibiotic) during the course of the hospital stay. The mean duration of hospital stay was 6.3 days in the antibiotic group. The mean duration of hospital stay was 4.2 days among the patients treated without 
antibiotics. Comparison of clinical features among the antibiotic and non antibiotic group showed that loose stools during the course of stay was seen in 7 cases of antibiotic group. All the cases (both antibiotic and non antibiotic group) have received supportive line of management, in the form of fluid and electrolyte management, free flow oxygen and aerosol therapy as per unit's protocol. All the patients have recovered. No death was reported [Table 2,3 \& 4],[fig 1,2].

\section{Discussion}

In our study $40(63.5 \%)$ cases were below 6months of age. Sex incidence analysis shows 71 are males, in other study also nearly $2 / 3$ are males [10]. Antibacterial medication are indicated in first time wheezers (which is primarily due to viral infections) only if there is coexisting bacterial infections, like secondary bacterial respiratory infection, urinary tract infection, acute otitis media or bacteremia [11]. When co-existing infection is suspected it has to be evaluated, investigated and treated in the same manner as if in a child without bronchiolitis. The fever due to RSV infection is of low grade and usually it disappear by the time the patients reach the tertiary care centers' [7]. The mean duration of stay is longer (6.3 days) in antibiotic received group when compared to non antibiotic group it is only 4.2 days This is similar to other studies [12], [13]. In our study $47(30 \%)$ of cases have received antibiotics. The incidence of loose stools is more in antibiotic group (7cases) compared to non antibiotic group (2cases). This may be due to the same respiratory virus causing gastroenteritis or it can be due to antibiotic associated diarrhea.

Coexisting serious bacterial infection is the concern by the clinicians. The incidence is low, with the majority being urinary tract infections in (1-7.5\%. of cases of) acute bronchiolitis [24]. The overall prevalence of U.T.I in general population is nearly $7 \%$ among infants and children in the age group of 2 to 24 months [24]. U.T.I has to be evaluated in the same manner like other infants when the child has bronchiolitis [14]. When antibiotics are started in referral cases before evaluation it can mask the symptoms of urinary tract infection. Before going for antibiotics like inj ceftriaxone or cefataxim the base line investigations like complete haemogram, plain x-ray chest (if the infant has respiratory distress), urine deposit and culture and sensitivity will be helpful to identify the presence or exclude the possibility of acute bacterial infection in a child admitted for acute bronchiolitis [15]. Another form of acute bacterial infection is acute otitis media following upper respiratory infection. Infants with acute respiratory infection can present to clinician with incessant cry due to various reasons. Incessant cry may be due to nose block, respiratory distress, acute otitis media, fever and abdominal pain due to aerophagia. In a study by Andrada MA et al [16] out of 42 cases studied 24 cases nearly 62 percent developed acute otitis media. Acute otitis media was not seen in our study group.

Three prospective studies [15] [17],[18], revealed the presence of low rates of serious acute bacterial infections (1-12 percent) in children with acute bronchiolitis. Study by K Thorrburn et al [23] shows that the antibiotic usage is around $40 \%$ in acute bronchiolitis group requiring invasive form of ventilator support. This can be due to ventilator associated pneumonia [19]. In our study all the patients have received non invasive mode of oxygen therapy. The infants requiring invasive mode of ventilator support because of affordability reason and the parent's convenience shifted to other centre and these cases were excluded from our study. One can get severe form of presentations in acute bronchiolitis in young infants $<3$ months as well as when there is co-infection with other respiratory viral pathogen like human metapneumo virus in the same child.

Early randomized control study [20],[21] has shown that no benefit of antibacterial therapy for the presence of crackles in children admitted as bronchiolitis. In developing countries especially in rural areas for cough and fever even before the reference infants are started with antibiotics as well as aerosol therapy. Presence of bilateral wheeze preceded by upper respiratory symptoms in an infant clearly points to viral respiratory syndrome. Sometimes one can get intermittent wheezing in respiratory syncytial viral infection. Localized wheeze, crackles, respiratory distress with other constitutional symptoms points to the presence of clinical pneumonia [8]. If appropriate antibacterial agent is not started in time infant with serious bacterial infection can deteriorate. Any child when nebulised with aerosol therapy can have crackles.

Retrospective studies have shown that there is low rate of serious bacterial infection $0-37$ percent in children admitted with acute bronchiolitis [17],[15],[22]. Bacterial pneumonia without consolidation is unusual in a child with respiratory distress [11]. Pneumonitis patches one can get even in viral infections. Normally lymphocyte count is more (in the total count) in infants 
and early childhood than in later life. In acute bacterial pneumonia the total count will be elevated significantly with polymorph predominance. In acute viral lower respiratory infections the total count may be normal or mild to moderately elevated with lymphocyte predominance [23]. In our study majority of the cases have lymphocyte predominance and 5 cases among the antibiotic group have polymorph predominance. Nearly $25 \%$ of cases admitted as acute bronchiolitis can have radiological changes like infiltrate that may be misinterpreted as possible bacterial infection [24],[25]. In our study 3 cases had pneumonitis. By careful interpretation viral and bacterial lesions in x-ray can be differentiated.

Presence of fever, young age, x-ray infiltrates and parent's anxiety are the major reasons for the antibiotics use. Seasonal flu also can present as acute bronchiolitis [3]. The x-ray findings will help to identify any coexisting acute bacterial infections in such children. Chlamydial infection is suspected if an infant between 1-3 months present with tachypnoea, elevated eosinophil count, and interstial or alveolar infiltrate without fever and wheeze [26]. The dose of azithromycin for chlamydial infection is about $20 \mathrm{mg} / \mathrm{kg} /$ day for 3 days. To identify the true incidence of the prevalence of chlamydial infection in our children less than 90 days of age the antenatal maternal colonization of vaginal tract with chlamydia has to be evaluated [26]. In the present study $47 \%$ [30] of cases have received either oral or parenteral antibiotis similar to the study conducted by Soumya et al [10]. All the patients in our study group have recovered completely. In our study nearly 34 (54\%) cases were anemic with the $\mathrm{Hb}$ level less than $11 \mathrm{gm} \%$ as per W.H.O cut off value for this age group. This can be explained due to physiological anemia of infancy which is seen in 2 months, with the continuation of anemia due to low reserve of iron as well as inadequate dietary supplement in children in lower socioeconomic group. Nutritional anemia (iron deficiency anemia) and under nutrition are significantly seen in rural areas [27].

Conclusion:with careful clinical assessment, correlation of laboratory support like complete haemogram, chest $\mathrm{x}$-ray interpretation one can exclude or identify coexisting acute bacterial infection in a child admitted with acute bronchiolitis. Various studies have shown that the presence of bacterial infection rate is very low. So we can judiciously use antimicrobials in clinical practice. Continuing medical education with recent updates helps to refine our clinical practice.
Funding: Nil, Conflict of interest: Nil

Permission from IRB: Yes

\section{Bibliography}

1. Kumar SG, Majumdar A, Kumar V, Naik BN, Selvaraj K, Balajee K. Prevalence of acute respiratory infection among under-five children in urban and rural areas of puducherry, India. J Nat Sci Biol Med. 2015 Jan-Jun; 6(1):3-6. doi: 10.4103/0976-9668.149069.

2. Putto A, Ruuskanen O, Meurman O. Fever in respiratory virus infections. Am J Dis Child. 1986 Nov; 140 (11):1159-63.

3. Clinical Signs and Symptoms of Influenza $\mid$ Health Professionals | Seasonal Influenza (Flu) [Internet]. [cited 2016 Dec 12]. Available from: http://www.cdc. gov/flu/professionals/acip/clinical.htm.

4. Vla WVL, Marks MI, Stutman HR. Respiratory syncytial virus puzzle: Clinical features, pathophysiology, treatment, and prevention. J Pediatr. 1992 Oct 1;121(4):503-10.

5. Rambaud-Althaus C, Althaus F, Genton B, D'Acremont V. Clinical features for diagnosis of pneumonia in children younger than 5 years: a systematic review and meta-analysis. Lancet Infect Dis. 2015 Apr;15(4):439-50. doi: 10.1016/S1473-3099(15) 70017-4. Epub 2015 Mar 11

6. Greenes DS, Harper MB. Low risk of bacteremia in febrile children with recognizable viral syndromes. Pediatr Infect Dis J. 1999 Mar;18(3):258-61.

7. Bronchiolitis $\mathrm{S}$ on $\mathrm{D}$ and $\mathrm{M}$ of. Diagnosis and Management of Bronchiolitis. Pediatrics. 2006 Oct 1;118(4):1774-93.

8. Hortal M, Mogdasy C, Russi JC, Deleon C, Suarez A. Microbial agents associated with pneumonia in children from Uruguay. Rev Infect Dis. 1990 Dec;12 Suppl 8:S915-22.

9. Howard WA. Differential Diagnosis of Wheezing in Children. Pediatr Rev. 1980 Feb 1;1(8):239-44.

10. S P, V S, Hk P, J C. Antibiotic prescribing pattern in paediatric in patients with first time wheezing., Antibiotic prescribing pattern in paediatric in patients with first time wheezing. Ital J Pediatr. 2011 Sep 5;37: 40. doi: 10.1186/1824-7288-37-40. 
11. Liebelt EL, Qi K, Harvey K. Diagnostic Testing for Serious Bacterial Infections in Infants Aged 90 Days or Younger With Bronchiolitis. Arch Pediatr Adolesc Med. 1999 May 1;153(5):525-30.

12. McMillan JA, Tristram DA, Weiner LB, Higgins AP, Sandstrom C, Brandon R. Prediction of the duration of hospitalization in patients with respiratory syncytial virus infection: use of clinical parameters. Pediatrics. 1988 Jan; 81(1):22-6.

13. Davies HD, Matlow A, Petric M, Glazier R, Wang EE. Prospective comparative study of viral, bacterial and atypical organisms identified in pneumonia and bronchiolitis in hospitalized Canadian infants. Pediatr Infect Dis J. 1996 Apr;15(4):371-5.

14. Hendaus MA, Alhammadi AH, Khalifa MS, Muneer E, Chandra P. Risk of urinary tract infection in infants and children with acute bronchiolitis. Paediatr Child Health. 2015 Jun-Jul;20(5):e25-9.

15. Kuppermann N, Bank DE, Walton EA, Senac MO, McCaslin I. Risks for Bacteremia and Urinary Tract Infections in Young Febrile Children With Bronchiolitis. Arch Pediatr Adolesc Med. 1997 Dec 1; 151 (12):1207-14.

16. Andrade MA, Hoberman A, Glustein J, Paradise JL, Wald ER. Acute otitis media in children with bronchiolitis. Pediatrics. 1998 Apr;101(4 Pt 1):617-9.

17. Levine DA, Platt SL, Dayan PS, Macias CG, Zorc JJ, Krief W, et al. Risk of serious bacterial infection in young febrile infants with respiratory syncytial virus infections. Pediatrics. 2004 Jun;113(6):1728-34.

18. Risk of serious bacterial infection in young febrile infants with respiratory syncytial virus infections. [Internet]. [cited 2016 Dec 10]. Available from: http:// www.medscape.com/medline/abstract/15173498.
19. 611.full.pdf [Internet]. [cited 2016 Dec 13]. Available from: http:// thorax. bmj. com/ content/ 61/7/611. full.pdf?61/7/611

20. Friis B, Andersen P, Brenøe E, Hornsleth A, Jensen A, Knudsen FU, et al. Antibiotic treatment of pneumonia and bronchiolitis. A prospective randomised study. Arch Dis Child. 1984 Nov 1;59(11):1038-45.

21. Titus MO, Wright SW. Prevalence of serious bacterial infections in febrile infants with respiratory syncytial virus infection. Pediatrics. 2003 Aug;112 (2):282-4.

22. Antonow JA, Hansen K, McKinstry CA, Byington CL. Sepsis evaluations in hospitalized infants with bronchiolitis. Pediatr InfectDisJ.1998 Mar;17(3):231-6.

23. Bronchiolitis Workup: Approach Considerations, WBC Count and Differential, Sepsis Workup [Internet]. [cited 2016 Dec 12]. Available from: http://emedicine. medscape. com/ article/961963-workup\#c8.

24. Purcell K, Fergie J. Concurrent serious bacterial infections in 912 infants and children hospitalized for treatment of respiratory syncytial virus lower respiratory tract infection. Pediatr Infect Dis J. 2004 Mar; 23(3):267-9.

25. Purcell K, Fergie J. Concurrent Serious Bacterial Infections in 2396 Infants and Children Hospitalized With Respiratory Syncytial Virus Lower Respiratory Tract Infections. Arch Pediatr Adolesc Med. 2002 Apr $1 ; 156(4): 322-4$.

26. Chlamydial Pneumonias: Overview, Pathophysiology, Epidemiology. 2016 Apr 24 [cited 2016 Dec 12]; Available from: http://emedicine. medscape. com/article/297351-overview.

27. Indian Pediatrics - Editorial [Internet]. [cited 2016 Dec 13]. Available from: http://www.indianpediatrics. net/apr2003/apr-293-295.htm.

\section{How to cite this article?}

Bala Gopal M, Babji NSR, Vinayagamoorthy V, Venkata NK. Clinical, laboratory profile \& antibiotic use in first time Wheezers in the tertiary care centre in the rural area.Int. J Pediatr Res. 2016;3(11):818825.doi:10.17511/ijpr.2016.i11.09. 